\title{
Comparison of ultraconserved elements (UCEs) to microsatellite markers for the study of avian hybrid zones: a test in Aphelocoma jays
}

\author{
Nicholas T. Vinciguerra ${ }^{1,5^{*}}$ (D) Whitney L. E. Tsai ${ }^{1}$, Brant C. Faircloth ${ }^{2,3}$ (1) and John E. McCormack ${ }^{1,4}$
}

\begin{abstract}
Objective: Hybrid zones are geographic regions where genetically distinct taxa interbreed, resulting in offspring of mixed ancestry. California Scrub-Jays (Aphelocoma californica) and Woodhouse's Scrub-Jays (A. woodhouseii) come into secondary contact and hybridize in western Nevada. Although previous work investigated divergence and gene flow between these species using a handful of microsatellite markers, the hybrid zone has not been studied using genome-scale markers, providing an opportunity to assess genome-wide introgression, test for a genetic basis for ecomorphological traits, and compare these estimates to those derived from microsatellites.

Results: Using variant sites flanking ultraconserved elements (UCEs), we performed population assignment and quantified hybrid ancestry for 16 individuals across the zone of secondary contact. Our study included 2468 SNPs distributed throughout the genome, allowing discrimination of genetic affinities of hybrid individuals that were similar to estimates from microsatellites. We show a relationship between bill and wing length and the genetic composition of individuals that was not found in prior work using microsatellites, suggesting a genetic basis for these traits. Our analyses demonstrate the utility of UCEs for the analysis of hybrid zones and provide a basis for future studies to identify the genomic architecture of speciation and phenotypic differences between these incipient species.
\end{abstract}

Keywords: Hybrid zones, Sequence capture, Population genomics, Ecomorphology

\section{Introduction}

Hybrid zones are windows into the process of species formation $[1,2]$. The standard model of speciation starts when the geographic range of an ancestral species is fragmented, and over time, phenotypes and genomes diverge through processes that change allele frequencies [3-5]. In some cases, ranges may shift, allowing divergent lineages to come back into secondary contact. These zones of secondary contact provide an opportunity to analyze the evolution of species barriers and trait variation [6] as well as to examine the genomic architecture of phenotypic differences [7, 8].

Molecular marker development is changing the way hybrid zones are studied, allowing genome scale

\footnotetext{
*Correspondence: nvinciguerra@sdsu.edu

${ }^{5}$ Present Address: Department of Biology, San Diego State University, San Diego, USA

Full list of author information is available at the end of the article
}

inferences. Whole genomes are becoming the gold standard for hybrid zone studies [9], but whole-genome data are still relatively expensive to collect and computationally demanding to analyze. Restriction site-associated DNA sequencing (RADSeq) data provide a more costeffective mechanism to collect genome-scale data and have been used extensively in hybrid zone work, but standard RADseq approaches do not work well with some types of DNA, especially degraded DNA from museum specimens. Ultraconserved elements (UCEs) are one type of molecular marker that have proved useful for collecting genomic-level phylogenetic data at both deep and shallow timescales [10,11]. UCEs have not often been used to study hybrid zones [but see 12,13], although they are a potentially useful way to collect noncoding DNA, similar to introns or microsatellites, at the genome scale. However, the target enrichment method for collecting UCEs-where the conserved elements act as a central anchor with variation primarily confined to 
the flanking regions-could make it difficult to assemble enough single nucleotide polymorphisms (SNPs) from UCEs to effectively study the recent divergences involved in most hybrid zones. Also, it is unclear to what extent UCE results may differ from population genetic markers like microsatellites because of the different mutational model that may underlie the evolution of UCE regions [14].

Here, we compare two molecular marker datasets across an avian hybrid zone to test if SNPs mined from UCEs give similar results to prior microsatellite work, and we use the genome-scale UCE data to assess whether some ecomorphological traits have a genetic basis. Previously, Gowen et al. [15] examined patterns of genetic variation across the distribution of California Scrub-Jay (Aphelocoma californica) and Woodhouse's Scrub-Jay (A. woodhouseii) using 13 microsatellite loci. These two recently-split species [16] show differences in bill shape: $A$. californica has a more heavy, hooked bill compared to the narrower and longer bill of $A$. woodhouseii; these differences are thought to be adaptations to local resources $[17,18]$. However, Gowen et al. [15] examined individuals of varying hybrid ancestry in the middle of the hybrid zone, where effects of the environment were minimized, and found that plumage traits were associated with genetic profile but bill traits were not. Failure to detect a correlation between genetic profile and bill divergence could have resulted from variance in the estimates of hybrid ancestry, because they were estimated from a small number of loci or because of stabilizing selection or plasticity in bill traits.

To determine if UCE data could shed light on this question, we first assessed whether sequence capture of UCEs would collect enough informative SNPs to determine genetic affinities of individuals. Then, we compared individual-level population assignment based on UCE data to that estimated from a previous dataset of 13 microsatellites for the same individuals [15]. Finally, we used our estimates of hybrid ancestry to test whether neutral genetic assignment could predict a suite of morphological traits, including those with a prior ecomorphological hypothesis. A correlation between hybrid ancestry and phenotypic traits in the middle of the hybrid zone would suggest these traits have an underlying genetic basis.

\section{Main text \\ Methods}

We obtained tissues from 16 vouchered museum specimens representing two individuals from each of eight populations of Aphelocoma californica, A. woodhouseii, and hybrids along a $722 \mathrm{~km}$ transect running northwest to southeast from the Sierra Nevada in northeastern California into west-central Nevada (Fig. 1; Table 1). This line corresponds to prior descriptions of the secondary contact zone $[15,19]$. Methods for DNA extraction, library preparation, sequence capture, and variant calling are provided in Additional file 1.

To assess population assignment and obtain estimates of individual-level hybrid ancestry ( $Q$ scores), we analyzed the SNP dataset in STRUCTURE v2.3.4 [20] using $K=2$. The $Q$ score reflects the estimated proportion of nuclear variation inherited from $A$. californica or A. woodhouseii. We ran three independent analyses for each value of $K=2$, using the admixture model and correlated allele frequencies. Each run had a burn-in of 100,000 generations and 1,000,000 Markov chain Monte Carlo generations post burn-in. We calculated per-locus $F_{\mathrm{ST}}$ on SNPs within the core UCE region, regions flanking UCEs, and microsatellites from Gowen et al. $[15,21]$ in the R package HIERFSTAT v0.04-22 [22] along with 1000 bootstrap replicates.

We conducted linear regression analyses of morphological traits with estimates of $Q$ scores from STRUCTURE for individuals within the hybrid zone, to minimize effects of environmental differences and determine the extent to which nuclear DNA variation could predict phenotypic differences. The morphological dataset included measurements of bill width, bill length, bill depth, wing length, tail length, and tarsus length $[15,21]$. Morphological characters were analyzed with principal components analysis in R v3.4.0 (http://www.r-project.org/) to identify axes defining the most variation. We assessed relationships between $Q$ scores and univariate and multivariate morphological traits at two spatial scales: across the oak woodland and pinyon-juniper woodland (hybrid cline, where there are environmental differences between ends of the cline) and within the immediate area of contact (where all individuals are experiencing the same habitat and the effect of environment as a source of variation is minimized).

\section{Results}

We collected ca. $1.9 \times 10^{8}$ raw reads from each Illumina library. We retained $99 \%$ of the read data after trimming of low-quality bases and removal of adapter contamination (see Additional file 2 for DNA sequencing statistics). After quality control, we assembled cleaned reads from specimen FMNH 333991 into consensus contigs and filtered to identify UCE loci, resulting in 4308 reference UCE sequences with an average length of $737 \mathrm{bp}$. Between 20 and $25 \%$ of cleaned reads were mapped to the reference for SNP calling. The rest of the reads were off-target sequence. An average of $10 \%$ of reads per individual were identified and removed as polymerase chain reaction duplicates. After SNP calling and variant filtration, our SNP dataset included 2468 SNPs, with one SNP out of every $500 \mathrm{bp}$, or 1-2 SNPs per UCE locus on 

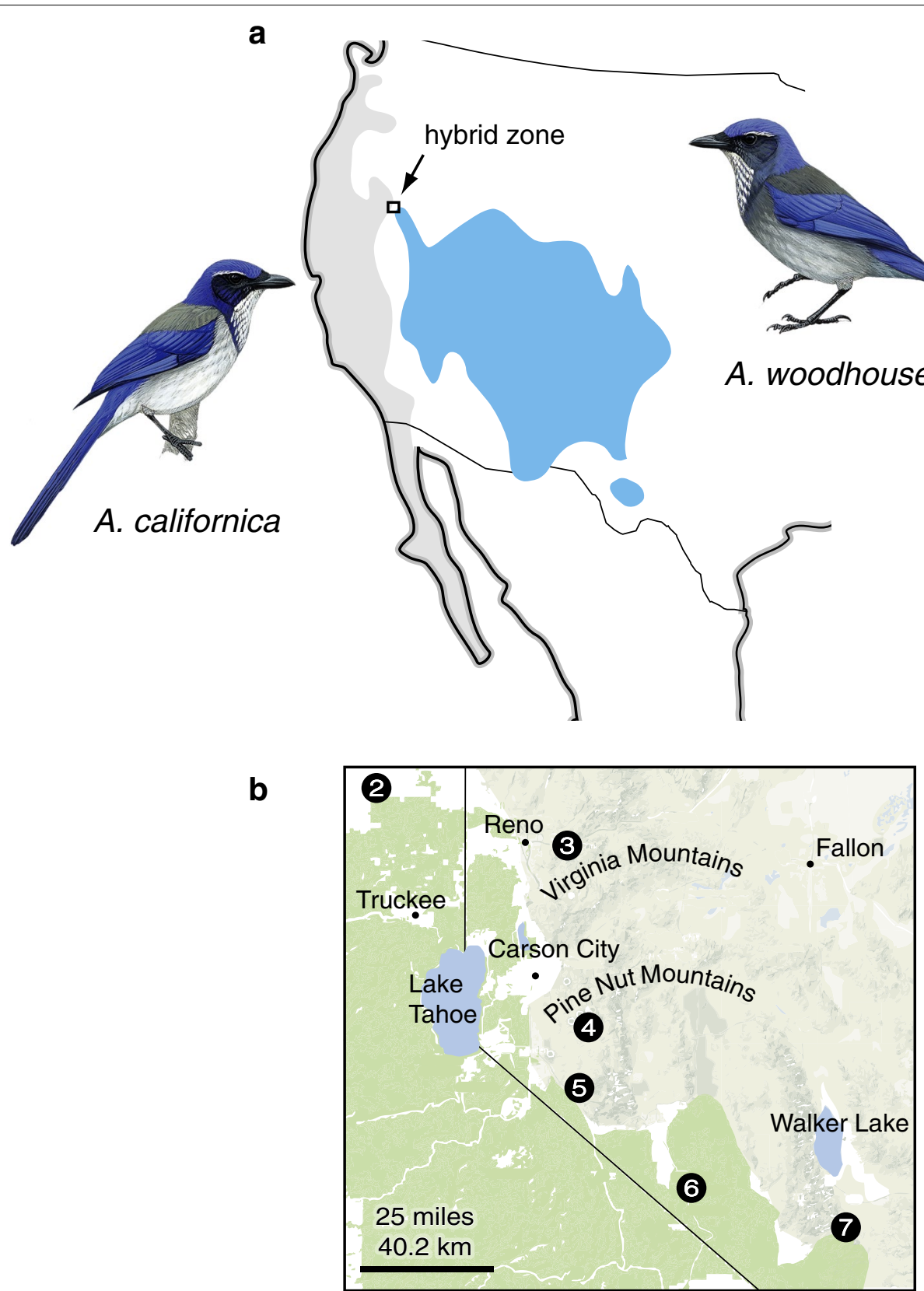

Fig. 1 Species range map and location of the Aphelocoma jay hybrid zone. a Range of A. californica (gray) and A. woodhouseii (blue). b Inset of sampling sites in the hybrid zone (sites 1 and 8 on the ends of the hybrid cline are not depicted in the inset). Map modified from McCormack et al. [29] with permission and bird illustrations reproduced by permission of Lynx Edicions as they appear in Handbook of the Birds of the World Alive [30]

average. Each SNP had an average depth of coverage of 69.73 per locus (SD: 39.66).

STRUCTURE analysis of SNP data revealed a distinct geographical pattern of genomic variation across the hybrid zone (Fig. 2a). The $722 \mathrm{~km}$ transect running from northeastern California into west-central Nevada showed a clear relationship between geographic locality and relative assignment probability to each species. Individuals from ends of the transect were assigned to either A. californica or $A$. woodhouseii with $\sim 99 \%$ probability, whereas individuals sampled from localities in between were assigned different proportions of hybrid ancestry. 
Table 1 Museum specimens collected along transect through hybrid zone and estimates of hybrid ancestry (Q)

\begin{tabular}{|c|c|c|c|c|c|c|c|c|c|}
\hline Museum $^{a}$ & Specimen no. & Collection date & Site $^{\mathbf{b}}$ & Location & Latitude & Longitude & Distance $(\mathbf{k m})^{c}$ & $Q_{\text {SNPs }}$ & $Q_{\text {msats }}$ \\
\hline FMNH & 333928 & 9 Jun. 1987 & 1 & Alturas, CA & 41.55 & -120.66 & 0 & 0.97 & 0.91 \\
\hline FMNH & 333930 & 9 Jun. 1987 & 1 & Alturas, CA & 41.55 & -120.66 & 0 & 1.00 & 0.94 \\
\hline FMNH & 333949 & 11 Jun. 1987 & 2 & Beckwourth, CA & 39.75 & -120.37 & 202 & 0.99 & 0.97 \\
\hline FMNH & 333950 & 11 Jun. 1987 & 2 & Beckwourth, CA & 39.75 & -120.37 & 202 & 0.99 & 0.95 \\
\hline FMNH & 333991 & 15 Jun. 1987 & 3 & Virginia Mts, NV & 39.50 & -119.63 & 279 & 0.76 & 0.67 \\
\hline FMNH & 333994 & 15 Jun. 1987 & 3 & Virginia Mts, NV & 39.50 & -119.63 & 279 & 0.76 & 0.07 \\
\hline MVZ & 179861 & 29 Sept. 2001 & 4 & Pine Nut Mts, NV & 39.06 & -119.57 & 292 & 0.44 & 0.63 \\
\hline MVZ & 179865 & 29 Sept. 2001 & 4 & Pine Nut Mts, NV & 39.06 & -119.57 & 292 & 0.52 & 0.61 \\
\hline $\mathrm{FMNH}$ & 333999 & 27 Jun. 1987 & 5 & Gardnerville, NV & 38.83 & -119.62 & 314 & 0.52 & 0.90 \\
\hline FMNH & 334000 & 27 Jun. 1987 & 5 & Gardnerville, NV & 38.83 & -119.62 & 314 & 0.55 & 0.77 \\
\hline MVZ & 178496 & 9 Dec. 1998 & 6 & Nye Canyon, NV & 38.57 & -119.21 & 353 & 0.02 & 0.03 \\
\hline MVZ & 178497 & 9 Dec. 1998 & 6 & Nye Canyon, NV & 38.57 & -119.21 & 353 & 0.06 & 0.07 \\
\hline MVZ & 179171 & 7 Dec. 1999 & 7 & Wassuk Range, NV & 38.46 & -118.65 & 384 & 0.03 & 0.04 \\
\hline MVZ & 179172 & 7 Dec. 1999 & 7 & Wassuk Range, NV & 38.46 & -118.65 & 384 & 0.11 & 0.06 \\
\hline FMNH & 334086 & 30 Mar. 1987 & 8 & Mt. Charleston, NV & 36.37 & -115.63 & 722 & 0.02 & 0.28 \\
\hline $\mathrm{FMNH}$ & 334087 & 30 Mar. 1987 & 8 & Mt. Charleston, NV & 36.37 & -115.63 & 722 & 0.01 & 0.02 \\
\hline
\end{tabular}

${ }^{a}$ FMNH, Field Museum of Natural History (Chicago); MVZ, Museum of Vertebrate Zoology (Berkeley)

${ }^{b}$ Sites 2-6 correspond to sampling localities in Fig. 1b. Specimens from sites 1 and 8 were collected outside the area of contact and hybridization

c Distance $(\mathrm{km})$ represents Euclidean distance across the hybrid zone

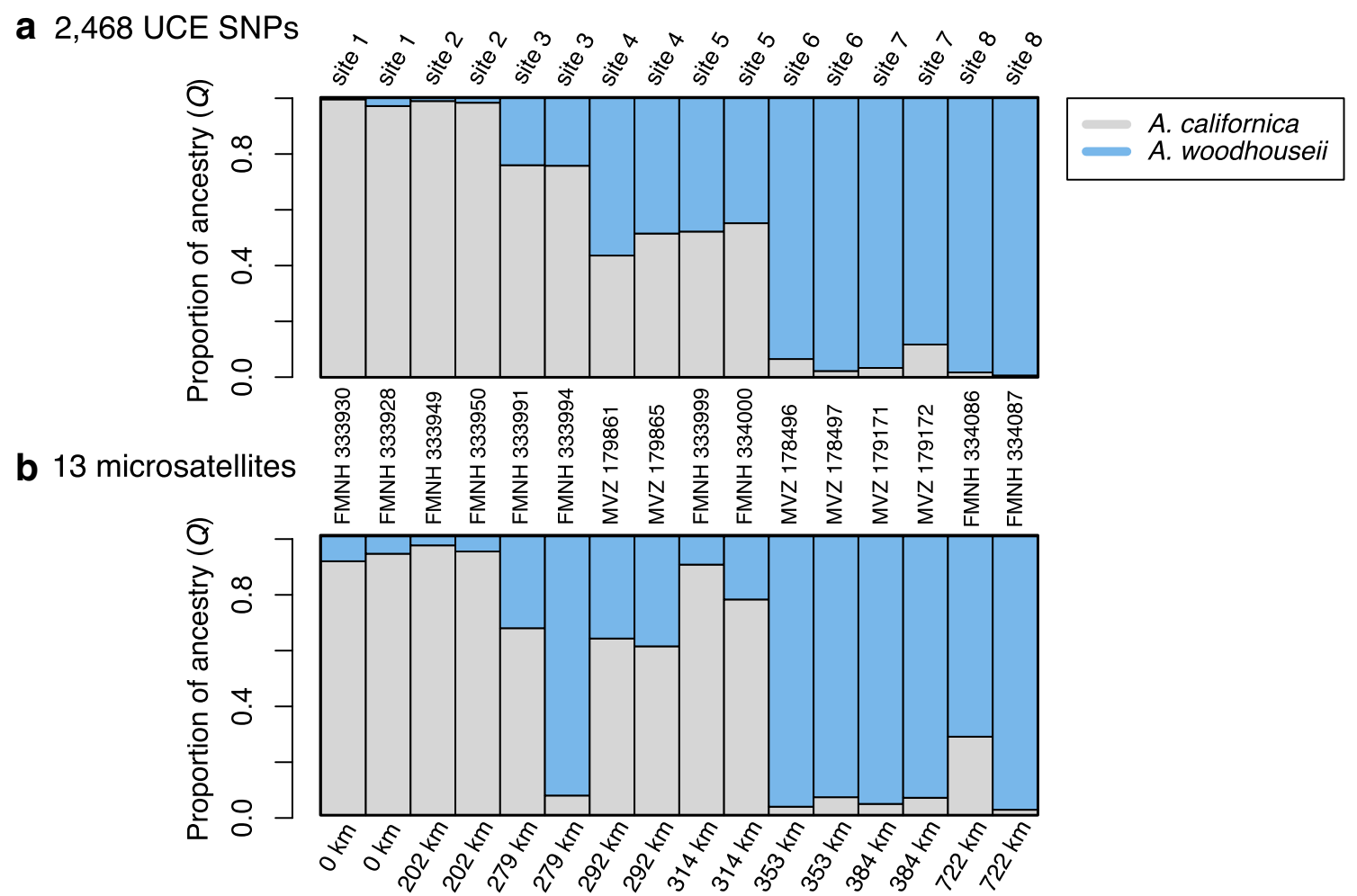

Fig. 2 STRUCTURE results ( $K=2$ ). STRUCTURE analysis based on (a) 2468 UCE SNPs, (b) 13 microsatellites [15, 21]. The y-axis indicates assignment probability to either the Aphelocoma californica genetic cluster (gray) or the A. woodhouseii genetic cluster (blue). Each colored vertical bar represents a vouchered museum specimen and numbers along the $\mathrm{x}$-axis indicate distance $(\mathrm{km})$ along the sampling transect 
Microsatellite-based $Q$ scores from prior research were significantly correlated with SNP-based $Q$ scores and explained $\sim 69 \%$ of the total variation in SNP-based estimates $(R$-squared $=0.688 ; p=<0.0005$; Additional file 3: Figure S1). However, a few individuals' genetic profiles differed between microsatellite and SNP data, and the qualitative pattern of genomic change across the hybrid zone was smoother with SNP data (Fig. 2).

Estimates of $F_{\mathrm{ST}}$ from SNPs flanking UCEs were greater than estimates from core UCE SNPs, as expected (flanking SNPs: average per-locus $F_{\mathrm{ST}}=0.108, \mathrm{SD}=0.008$; core SNPs: average per-locus $F_{\mathrm{ST}}=0.073, \mathrm{SD}=0.013$; Additional file 4: Figure S2). Microsatellite-based $F_{\mathrm{ST}}$ estimates were intermediate between these values, with larger variance likely due to smaller locus sample size (average per-locus $F_{\mathrm{ST}}=0.129, \mathrm{SD}=0.042$ ).

Although sample sizes were small, there were significant correlations between estimates of hybrid ancestry and two ecomorphological traits: wing length and bill length (Additional file 5: Table S2). For the dataset of 12 hybrid individuals (i.e., excluding the ends of the transect), wing length explained $\sim 52 \%$ of the variation in $Q$ score $(R$-squared $=0.524 ; p=0.008)$. Narrowing the focus to the area of contact, where environmental differences are minimized, $Q$ score explained $\sim 67 \%$ of the variation in bill length $(R$-squared $=0.669 ; p=0.047)$.

\section{Discussion}

These results add to previous findings demonstrating that UCEs are informative genomic markers for addressing questions at shallow evolutionary timescales [11, 23-26] such as the divergences observed in hybrid zone studies $[12,13]$. We show that SNPs mined from UCEs provide sufficient variation to infer patterns of divergence between incipient species in secondary contact with ongoing gene flow. Specifically, we use genome-scale data to confirm a smooth transition in genetic ancestry from A. californica to $A$. woodhouseii across a geographic cline, with individuals in the two middle sites (i.e. 4, 5) having nearly 50/50 ancestry estimated using our SNP data.

We also show that hybrid ancestry estimated from $\sim 2400$ SNPs drawn from UCEs are correlated with estimates from the 13 microsatellites, especially for individuals predicted to be of pure or nearly pure ancestry of one species (i.e. those at the ends of the cline). Individuals in the 4 middle sites (i.e. sites 3-6) showed less correlation between SNP-based and microsatellite-based $Q$ scores than individuals at the 4 end sites (average difference in middle sites $=0.21$; average difference of end sites $=0.07$ ), although sample sizes were low and this effect was not significant $(p=0.11)$. While it is difficult to know which $Q$ score is the more accurate measure because we do not know the true ancestry of individuals, hybrid values from SNP data were more similar for the two individuals within sites (average difference between individuals within sites for SNPs $=0.03$; and for microsatellites $=0.14, p=0.17$ ), suggesting SNP data might be, if not more accurate, at least more precise than the microsatellite data.

More precise estimates of hybrid ancestry might help determine whether morphological traits have a genetic basis. Building off prior work on these species $[15,17$, 18 ], we reasoned that we could minimize the effect of environment as a cause of the phenotypic differences between species by restricting the analysis to the zone of secondary contact, where individuals with a variety of hybrid scores experience the same environment. If phenotypic differences were driven by genetic mechanisms, then an individual with a higher proportion of $A$. californica DNA would also be more likely to have a short and stout bill, provided bill shape is under genetic control. However, there is considerable room for noise in this kind of analysis, because bill size and shape are likely polygenic [27] and the randomness of recombination means that an individual with a high proportion of $A$. californica DNA might nevertheless have inherited $A$. woodhouseii genes that affect bill dimensions. Despite these caveats, and our low sample size, we found an association between hybrid score and both bill length and wing length. This finding sets the stage for follow-up studies with larger sample sizes where pure individuals and natural backcrosses could be analyzed using whole-genome analyses to study the genomic underpinnings of these traits.

Hybrids zones are natural laboratories for investigating speciation and the genomic architecture of phenotypic traits. Here, we show that UCEs, and SNPs contained within them, are promising markers for the study of hybrid zones. Although UCEs do not typically occur within protein-coding genes when collected from vertebrate taxa, SNPs within UCE loci are amenable for studying so-called "neutral" processes in a similar manner as they are used currently in phylogeography and phylogenetics. Moreover, UCEs are universal across major taxonomic groups, abundant throughout the genome, efficient to collect, and useful with available tissue types, including degraded DNA extracted from museum specimens [28]. For these reasons, UCEs provide a useful genomic marker for studies seeking to understand the nature of divergence and gene flow between lineages in secondary contact.

\section{Limitations}

Whole genome sequences and more individuals would be needed to identify the genomic underpinnings of speciation and phenotypic differences between these species. 


\section{Additional files}

Additional file 1. Methods for DNA extraction, library preparation, sequence capture, and variant calling.

Additional file 2: Table S1. Statistics on sequenced DNA data for individual museum specimens.

Additional file 3: Figure S1. Linear regression of hybrid ancestry $(Q$ scores) estimates.

Additional file 4: Figure S2. Bootstrapped average per-locus $F_{\mathrm{ST}}$ values. Additional file 5: Table S2. $R^{2}$ values between hybrid index and phenotypic traits.

Additional file 6. VCF file of SNPs from UCE loci.

\section{Abbreviations}

RADSeq: restriction site-associated DNA sequencing; UCE: ultraconserved element; SNP: single nucleotide polymorphism; SD: standard deviation.

\section{Acknowledgements}

Dave Willard at the Field Museum of Natural History (FMNH) and Carla Cicero at the Museum of Vertebrate Zoology loaned tissues, while FMNH and Steve Cardiff at the Museum of Natural Science at Louisiana State University assisted with study skin loans. Adolfo Navarro, Town Peterson, Carla Cicero, and Ned Johnson did the field collecting. We thank John Klicka for assistance with obtaining specimens in Nevada. Uma Dandekar at the UCLA Genotyping and Sequencing Core assisted with Illumina sequencing. We thank Robert Wayne, Tom Smith, Brad Shafer, and Michael Alfaro in the UCLA Department of Ecology and Evolutionary Biology for allowing access to a Bioruptor they purchased. For advice with data analyses, we thank James Maley and Eugenia Zarza. We thank Paul Maier for help with $F_{\mathrm{ST}}$ bootstrapping.

\section{Authors' contributions}

JEM and BCF conceived the idea and study design; NTV and WLET generated the data; NTV analyzed the data; NTV, WLET, BCF, and JEM wrote the paper; and JEM and BCF contributed substantial materials, resources, and funding. All authors read and approved the final manuscript.

\section{Funding}

This study was funded by National Science Foundation (NSF) grants DEB1244739 and DEB-1652979. NSF did not participate in the design, preparation, analysis, interpretation of data, or writing of the manuscript.

\section{Availability of data and materials}

The SNP dataset analyzed in this study is available in Additional file 6. The microsatellite dataset and morphological dataset are available for download from Dryad, https://doi.org/10.5061/dryad.57f48 [21].

\section{Ethics approval and consent to participate}

Vouchered museum specimens were used in this research.

\section{Consent for publication}

Not applicable.

\section{Competing interests}

The authors declare that they have no competing interests.

\section{Author details}

${ }^{1}$ Moore Laboratory of Zoology, Occidental College, Los Angeles, CA, USA.

${ }^{2}$ Department of Biological Sciences, Louisiana State University, Baton Rouge,

LA, USA. ${ }^{3}$ Museum of Natural Science, Louisiana State University, Baton Rouge,

LA, USA. ${ }^{4}$ Biology Department, Occidental College, Los Angeles, CA, USA.

${ }^{5}$ Present Address: Department of Biology, San Diego State University, San

Diego, USA.

Received: 30 April 2019 Accepted: 15 July 2019

Published online: 24 July 2019

\section{References}

1. Harrison RG. Hybrid zones and the evolutionary process. Oxford: Oxford University Press; 1993

2. Hewitt GM. Hybrid zones-natural laboratories for evolutionary studies. Trends Ecol Evol. 1993;3:158-67.

3. Mayr E. Animal species and evolution. Cambridge: Belknap Press; 1963.

4. Newton I. The speciation and biogeography of birds. London: Academic Press; 2003

5. Price T. Speciation in birds. Greenwood Village: Roberts and Company; 2008.

6. Barton NH, Hewitt GM. Analysis of hybrid zones. Annu Rev Ecol Evol Syst. 1985;16:113-48.

7. Poelstra JW, Vijay N, Bossu CM, Lantz H, Ryll B, Müller I, Baglione V, Unneberg P, Wikelski M, Grabherr MG, Wolf JB. The genomic landscape underlying phenotypic integrity in the face of gene flow in crows. Science. 2014;344:1410-4.

8. Toews DP, Taylor SA, Vallender R, Brelsford A, Butcher BG, Messer PW, Lovette IJ. Plumage genes and little else distinguish the genomes of hybridizing warblers. Curr Biol. 2016;26:2313-8.

9. Ellegren H, Smeds L, Burri R, Olason PI, Backström N, Kawakami T, Künstner A, Mäkinen H, Nadachowska-Brzyska K, Qvarnström A, Uebbing $\mathrm{S}$, Wolf JB. The genomic landscape of species divergence in Ficedula flycatchers. Nature. 2012;491:756-60.

10. McCormack JE, Harvey MG, Faircloth BC, Crawford NG, Glenn TC, Brumfield RT. A phylogeny of birds based on over 1,500 loci collected by target enrichment and high-throughput sequencing. PLOS ONE. 2013;8:e54848.

11. Smith BT, Harvey MG, Faircloth BC, Glenn TC, Brumfield RT. Target capture and massively parallel sequencing of ultraconserved elements for comparative studies at shallow evolutionary time scales. Syst Biol. 2014;63:83-95.

12. Oswald JA, Harvey MG, Remsen RC, Foxworth DU, Dittmann DL, Cardiff SW, Brumfield RT. Evolutionary dynamics of hybridization and introgression following the recent colonization of Glossy Ibis (Aves: Plegadis falcinellus) into the New World. Mol Ecol. 2019. https://doi.org/10.1111/ mec.15008.

13. Winker K, Glenn TC, Withrow J, Sealy SG, Faircloth BC. Speciation despite gene flow in two owls (Aegolius ssp.): evidence from 2517 ultraconserved element (UCE) loci. Auk: Ornithol Adv. 2019. https://doi.org/10.1093/auk/ ukz012.

14. Bejerano G, Pheasant M, Makunin I, Stephen S, Kent WJ, Mattick JS, Haussler D. Ultraconserved elements in the human genome. Science. 2004;304:1321-5

15. Gowen FC, Maley JM, Cicero C, Peterson AT, Faircloth BC, Warr TC, McCormack JE. Speciation in Western Scrub-Jays, Haldane's rule, and genetic clines in secondary contact. BMC Evol Biol. 2014;14:135.

16. Chesser RT, Burns KJ, Cicero C, Dunn JL, Kratter AW, Lovette IJ, Rasmussen PC, Remsen JV, Rising JD, Stotz DF. Fifty-seventh Supplement to the American Ornithologists' Union Check-list of North American Birds. Auk: Ornithol Adv. 2016;133:544-60.

17. Peterson AT. Adaptive geographical variation in bill shape of scrub jays (Aphelocoma coerulescens). Am Nat. 1993;142:508-27.

18. Bardwell E, Benkman CW, Gould WR. Adaptive geographic variation in Western Scrub-Jays. Ecology. 2001;82:2617-27.

19. Pitelka FA. Speciation and ecological distribution in American jays of the genus Aphelocoma. California: University of California Publications in Zoology; 1951.

20. Pritchard JK, Stephens M, Donnelly P. Inference of population structure using multilocus genotype data. Genetics. 2000;155:945-59.

21. Gowen FC, Maley JM, Cicero C, Peterson AT, Faircloth BC, Warr TC, McCormack JE. Data from: speciation in Western Scrub-Jays, Haldane's rule, and genetic clines in secondary contact. Dryad Digit Repos. 2014. https://doi. org/10.5061/dryad.57f48.

22. Goudet J. Hierfstat, a package for $\mathrm{R}$ to compute and test hierarchical F-statistics. Mol Ecol Notes. 2015;5:184-6.

23. Oswald JA, Harvey MG, Remsen RC, Foxworth DU, Cardiff SW, Dittmann DL, Megna LC, Carling MD, Brumfield RT. Willet be one species or two? A genomic view of the evolutionary history of Tringa semipalmata. Auk: Ornithol Adv. 2016;133:593-614.

24. Zarza E, Faircloth BC, Tsai WL, Bryson RW Jr, Klicka J, McCormack JE. Hidden histories of gene flow in highland birds revealed with genomic markers. Mol Ecol. 2016;25:5144-57. 
25. Harvey MG, Aleixo A, Ribas CC, Brumfield RT. Habitat association predicts genetic diversity and population divergence in Amazonian birds. Am Nat. 2017;190:631-48.

26. Mason NA, Olvera-Vital A, Lovette IJ, Navarro-Sigüenza AG. Hidden endemism, deep polyphyly, and repeated dispersal across the Isthmus of Tehuantepec: diversification of the White-collared Seedeater complex (Thraupidae: Sporophila torqueola). Ecol Evol. 2018;8:1867-81.

27. Lamichhaney S, Berglund J, Almén MS, Maqbool K, Grabherr M, MartinezBarrio A, Promerová M, Rubin CJ, Wang C, Zamani N, Grant BR. Evolution of Darwin's finches and their beaks revealed by genome sequencing. Nature. 2015;518:371-5.

28. McCormack JE, Tsai WL, Faircloth BC. Sequence capture of ultraconserved elements from bird museum specimens. Mol Ecol Resour. 2016;16:1189-203.
29. McCormack JE, Heled J, Delaney KS, Peterson AT, Knowles LL. Calibrating divergence times on species trees versus gene trees: implications for speciation history of Aphelocoma jays. Evolution. 2011;65:184-202.

30. del Hoyo J, Elliott A, Sargatal J, Christie DA, de Juana E, editors. Handbook of the birds of the world alive. Barcelona: Lynx Edicions; 2019.

\section{Publisher's Note}

Springer Nature remains neutral with regard to jurisdictional claims in published maps and institutional affiliations.
Ready to submit your research? Choose BMC and benefit from:

- fast, convenient online submission

- thorough peer review by experienced researchers in your field

- rapid publication on acceptance

- support for research data, including large and complex data types

- gold Open Access which fosters wider collaboration and increased citations

- maximum visibility for your research: over $100 \mathrm{M}$ website views per year

At BMC, research is always in progress.

Learn more biomedcentral.com/submissions 